\title{
COMPARISON OF THE RESULTS OF ATL AND RESPIRATORY PARAMETERS BEFORE AND AFTER THE ANTI-G TRAINING
}

\author{
Mieczysław WOJTKOWIAK, Marcin BIERNACKI \\ Military Institute of Aviation Medicine, Department of Physiology, Warsaw, Poland
}

Source of support: Own sources

Author's address: M. Wojtkowiak, Military Institute of Aviation Medicine. Department of Physiology, Krasinskiego 54/56 Street, 01-755 Warsaw, Poland, e-mail: mwojtkowiak@wiml.waw.pl

Introduction: The analysis of Acceleration Tolerance Limit (ATL), carried out in previous years during tests in a human centrifuge, showed a sustained reduction in this index, which was associated with a decrease in the intensity of targeted physical exercises preventing the occurrence of back pain.

Methods: The obtained results were compared with the results recorded after the physical training - Anti-G Straining Maneuver (AGSM) - in the Polish Military Conditioning Training Center (WOSzK). The study on sustaining ATL over the years included 11 pilots prepared to fly MIG-29. The study subjects who made the reference material were the same pilots who took part in the first training conducted in the training center 3-4 years earlier. In addition to the standard Gradual Onset Rate (GOR) tests performed in the human centrifuge, special attention was paid to the measurements of respiratory parameters, the differences in which could significantly affect the performance of the L-1 maneuver, namely: lung vital capacity, time of apnea holding, maximum pressure of air expiration against the closed glottis, and the Flack's Test.

Results: Following the training, special breathing indices showed statistically significant differences. They were associated with the use of the training program focusing on AGSM increase. The program was introduced in the WOSzK to the annually conducted training programs for jet pilots. The comparative analysis of the ATL results in pilots after some years since the training in WOSzK with the results obtained before and after the training showed a slight decrease in this index, which - according to the $+\mathrm{Gz}$ tolerance scale ranged within good limits.

Tables: 2 • Figures: 2 - References: 23 - Full-text PDF: http://www.pjamp.com • Copyright (C) 2013 Polish Aviation Medicine Society, ul. Krasińskiego 54/56, 01-755 Warsaw, license WIML • Indexation: Index Copernicus, Polish Ministry of Science and Higher Education 
Discussion: The comparative analysis of the ATL results obtained before the training and some years after it showed a statistically significant decrease. As shown by the surveys conducted among the analyzed group of pilots, flight dynamics load was lower compared to the examination performed after a period of 3-4 years.

Conclusions: The exercises introduced in the WOSzK which aimed to increase AGSM influenced significantly the level of ATL and selected respiratory parameters.

It can be assumed that the value of ATL may be affected by the dynamics of flights with acceleration and performing AGSM exercises from time to time. It is believed that the results obtained after some years were associated with performing frequent flights under $+\mathrm{Gz}$ acceleration and with the sustained training effects related to the L- 1 maneuver.

Corrections in performing the L-1 maneuver introduced by some pilots can, over time, during subsequent maneuvers under $+G z$ acceleration, cause early fatigue, reduced response speed, and decreased effectiveness of the physiological mechanisms of system compensation and ATL.

Keywords: +Gz acceleration, ATL after some years, AGSM training

\section{INTRODUCTION}

The values of the ATL results, obtained during routine tests in the human centrifuge at the Military Institute of Aviation Medicine (WIML), showed a decline progressing over the years. A statistical analysis of the results, carried out in 2007, revealed no statistically significant differences in comparison with similar studies conducted in 1994-2000 $[16,20]$. The above-mentioned changes in ATL suggested, inter alia, decreased functional efficiency of the cardiovascular system or excessive fatigue. A more thorough medical examination with the use of modern equipment indicated a better health condition of the pilots, but did not fully solve the problem of a progressive decrease in the $+\mathrm{Gz}$ tolerance. The literature on the subject indicates that a sustaining decline in terms of ATL may be associated with lower intensity of targeted exercises preventing the occurrence of back pain $[11,15,22]$. It was suggested that the best solution would be the introduction of a special workout into the pilot training program developing such motor characteristics as strength, speed endurance, speed, and exercises aimed at preparing the pilots to perform the $L-1$ maneuvers $[7,23]$. These issues resulted in the development of the training program, which was introduced at a three-week high-altitude training camp [19]. The basic element of the training was the performance of cardiopulmonary resuscitation maneuvers such as AGSM. It is known from the literature $[2,3,5,8,12,13,21]$ that the effectiveness of these maneuvers depends on the appropriate tension of the muscles, including the pressure of air expiration against the partially or fully closed glottis. This maneuver involves severe muscle tensioning, adapted to the circumstances of acceleration, in correlation with a specific rhythm of breathing, which is the most important factor in this exercise. It should be noted that the efficiency of the L-1 maneuver was confirmed in many studies on ATL in the human centrifuge $[4,5,21]$. It was necessary, however, to check whether the pilots, after some years elapsed, still experienced the obtained benefits on the constant level, or they lost such benefits due to the lack of appropriately targeted and systematically practiced physical exercises.

The aim of this research was to conduct comparative studies of breathing parameters obtained at the high-altitude training camp with the ATL results recorded in the human centrifuge before and after some years since the completion of an effective and properly conducted the L-1 maneuver training.

\section{METHODS}

Eleven pilots prepared to fly MiG-29 aircrafts were included in the comparative studies on sustaining ATL over the years.

The subjects who were the reference material were the same pilots who first took part in the control examination and later were trained at the WOSzK. Further examination was conducted three or four years after the training.

The subjects were aged 29-31 years. They all had valid results of periodical medical examina- 
tions obtained in Military Medical Aviation Commission (WKLL), permitting them to participate in the ATL tests conducted in the human centrifuge. The pilots consented to be subjected to additional examinations.

Ethical approval was obtained from the Ethics Commission of the Military Institute of Aviation Medicine. The determination of ATL in the human centrifuge at the Military Institute of Aviation Medicine (WIML) was performed with the application of a commonly known GOR method [8]. The pilots did not wear the anti-G trousers and did not perform the L-1 maneuver during the GOR. The human centrifuge examinations were performed few days before and after the training in WOSzK. The physiological examination consisted of $H R$, RR, Step Test and respiratory parameters.

The same program was used to perform additional trainings of the L-1 maneuver. In addition to the standard physiological tests performed in the high-performance human centrifuge, which are not described in this work, special attention was paid to the measurements of respiratory parameters, the differences in which could significantly affect the performance of the L-1 maneuver, namely:

- vital capacity of the lungs;

- time of apnea holding measured by a chronometer;

- maximum air pressure of air expiration against the completely closed glottis, defined by the most elevated mercury pillar during expiration;

- Flack's Test determining the maximum duration of $30 \mathrm{mmHg}$ pressure during expiration.

The above measurements were taken using the standard apparatus for testing the vital capacity of the lungs and a mercury manometer. The differences in the results obtained before and after the course in the training center, and after some years following its completion, are presented in absolute values in the tables and on the charts contained below.

For the purpose of data analysis, ANOVA was used with repeated measures. The analysis of simple effects was carried out using post-hoc comparisons with the Bonferonni correction.

\section{RESULTS}

As a result of the physical training, which was developed by Wojtkowiak [19], confirmed increase in the ATL and respiratory parameters.

First, the changes in ATL were subjected to an analysis depending on the moment in time, namely: before the training, after the training, after 3-4 years since the completion of the training (Tab. 1.).

Tab. 1. ATL values depending on the order of measurements.

\begin{tabular}{lcc}
\hline Order of measurements & $\mathbf{M}$ & $\mathbf{S E}$ \\
\hline Before the training & 7.233 & .123 \\
\hline After the training & 7.575 & .139 \\
\hline After 3-4 years & 6.850 & .116 \\
\hline
\end{tabular}

The results of the analysis indicate that the moment of examination significantly affected the ATL values, $F(2.22)=15.303, p<0.001, \eta^{2} p=0.582$. The analysis of simple effects using post-hoc comparisons with the Bonferroni correction showed that the ATL value before the training ( $M=7.233$ ) was significantly lower compared to the ATL result after the training $(M=7.575), p<0.05$, and was higher in comparison to the ATL value after a 3-4 year break $(M=6.850)$ $\mathrm{p}<0.05$. In addition, the GTP value after the training $(M=7.575)$ was significantly higher in comparison to the result obtained after the break $(M=6.850) p<0.05$. These relationships are illustrated in Fig. 1.

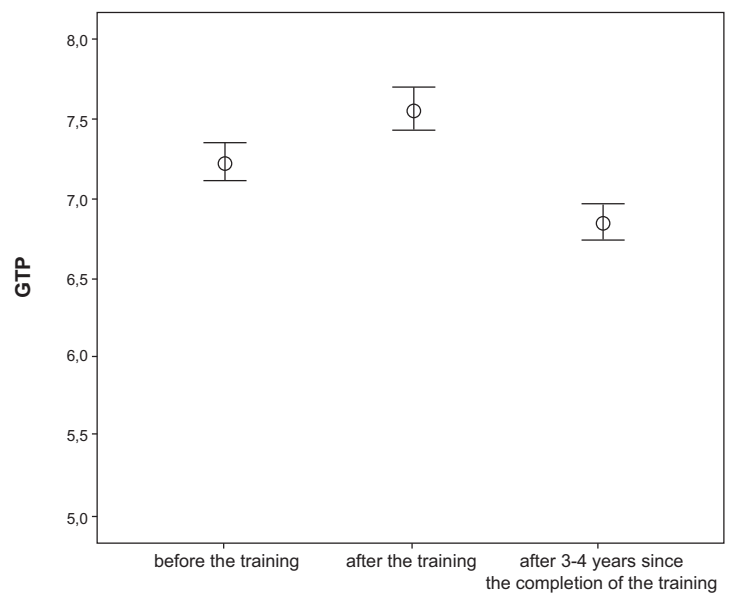

Fig. 1. GTP before, during and after the training.

Subsequently, respiratory parameters were analyzed. Descriptive statistics are presented in the Tab. 2.

Tab. 2. ATL values depending on the order of measurements.

\begin{tabular}{lcccccc}
\hline & \multicolumn{2}{c}{ Before the training } & \multicolumn{2}{c}{ After the training } & \multicolumn{2}{c}{ After a 3-4-year break } \\
\hline Breathing indexes & M & SE & M & SE & M & SE \\
\hline Lung vital capacity $(\mathbf{m l})$ & 5056.667 & 136.245 & 5578.333 & 111.361 & 5371.667 & 155.124 \\
\hline Time of apnea holding $(\mathbf{s})$ & 42.250 & 2.487 & 61.583 & 2.414 & 52.583 & 2.039 \\
\hline $\begin{array}{l}\text { Maximum pressure of air expiration on the } \\
\text { closed glottis (mmHg) }\end{array}$ & 47.200 & 2.154 & 54.000 & 1.892 & 52.200 & 2.250 \\
\hline Flack's Test $(\mathbf{s})$ & 31.545 & 1.303 & 46.636 & 1.316 & 42.727 & 1.784 \\
\hline
\end{tabular}


The changes in the values of vital capacity depending on the moment in time of performing the examination were analyzed. The results of the analysis indicate that the time of the examination significantly affected the value of lung vital capacity, $F(2.22)=15.250, p<0.001, \eta^{2} p=0.581$. The analysis of simple effects using post-hoc comparisons with the Bonferroni correction showed that the value of lung capacity before the training ( $M=5056.667)$ was significantly lower compared to the maximum value after the training $(M=5578.333), p<0.001$, and was significantly lower compared to the value obtained after the break $(M=5371.667)$. The value of vital capacity after the training $(M=5578.333)$ was not significantly different compared to the value recorded after the break $(M=5371.667)$.

The next step of the study involved an analysis of the changes in the values of the maximum air pressure depending on the time of performing the test. The results of the analysis indicate that the time factor influenced significantly, at the level of statistical trend, the value of the maximum air pressure, $F(2.18)=2.803, p=0.087, \eta^{2} p=0.238$. The analysis of simple effects using post-hoc comparisons with the Bonferroni correction showed that the value of the maximum air pressure before the training ( $M=47.200)$ was significantly lower compared to the maximum air pressure after the training $(M=54.000), p<0.01$, and did not differ significantly from the value of the maximum air pressure after the break $(M=52.200)$. Similarly, the maximum air pressure after the training $(M=47.200)$ was not significantly different compared to the value obtained after a 3-4-year break ( $M=52.200)$.

Also, the changes in the values of apnea were analyzed depending on when the measurements were performed. The results of the analysis indicate that the time of examination significantly affected the value of apnea holding, $F(2.22)=19.177$, $p<0.001, \eta^{2} p=0.635$. The analysis of simple effects using post-hoc comparisons with the Bonferroni correction showed that the value of apnea holding before the training $(M=42.250)$ was significantly lower compared to the ATL value recorded after the training $(M=61.583), p<0.01$, and was lower in comparison to apnea holding after the break $(M=52.583), p<0.05$. In addition, the value of apnea after the training $(M=61.583)$ was significantly higher in comparison to the value observed after the break $(M=52.583), p<0.05$.

Finally, the changes in the values obtained in the Flack's Test were analyzed depending on when the test was conducted. The results of the analysis indicate that the moment of taking the measurements significantly affected the value of the
Flack's Test, $F(2.20)=27.855, p<0.001, \eta^{2} p=0.736$. The analysis of simple effects using post-hoc comparisons with the Bonferroni correction showed that the value obtained in the Flack's Test before the training $(M=31.545)$ was significantly lower compared to the value after the training $(M=46.636)$, $p<0.001$, and was lower in comparison to the result noted after the break $(M=42.727), p<0.01$. In addition to this, the Flack's Test value after the training $(M=46.636)$ was significantly higher in comparison to the value obtained after the break $(M=42.727)$, $p<0.05$.

\section{DISCUSSION}

Table 1 presents the results of examination of the pilots directed to WOSzK for AGSM training. All pilots had good ATL resulting from frequent performance of flight maneuvers under acceleration. Thus, an increase in ATL, in comparison to the input values of this index, observed after physical training was small, but statistically significant.

The comparative analysis of the ATL results obtained before the training and some years after it showed a statistically significant decrease. Such statistically significant difference required justification. As shown by the surveys conducted among the analyzed group of pilots, flight dynamics load was lower compared to the examination performed after a period of 3-4 years. In addition, the pilots did not follow the full program comprising all the exercises used in the AGSM training and did not practice them regularly.

However, they systematically applied various individually introduced forms of exercises, which did not stimulate the increase in ATL. A detailed description of exercises aimed at improving AGSM was presented in "Wybrane ćwiczenia fizyczne przygotowujące pilotów do wykonywania prób krążeniowo- oddechowych zwiększających tolerancję przyspieszenia" by M. Wojtkowiak [19]. According to the author, the training methods confirmed a significant increase in ATL after the training in the Military Conditioning Training Center and were introduced into the training program for jet pilots. Beneficial effects of physical training targeted at an increase in ATL were also dealt with by other authors $[9,14]$.

The conducted research, therefore, goes back to the previous years, when carrying out the first training courses for pilots of high-performance aircrafts aimed at increasing AGSM was commenced [18].

High values of physiological indices that were obtained as a result of the special training of $11 \mathrm{pi}-$ lots mainly related to respiratory parameters. The 
analysis of these results carried out after a long period of time from the training in WOSzK also made it possible to check keeping up the correctness and effectiveness of tension L-1 type maneuvers.

Analyzing the results of long-term studies on pilots performing L-1 maneuvers in a human centrifuge it was concluded that higher effectiveness in obtaining beneficial effects as regards ATL depended to a large extent on the time of sustaining the learned elements of this maneuver. In this respect, what was important was learning (the first time) through the proper performance of $L-1$, which should be then enhanced on training camps during the realization of the training programs for pilots of high-performance aircrafts. It is worth emphasizing that the AGSM training is conducted every year in the high mountain conditioning centre for pilots. The researched group went through this training.

The results shown in Fig. 2 illustrate the changes in respiration indices at various stages of the study.

Analyzing the vital capacity test parameters after the training in the training center, an increase
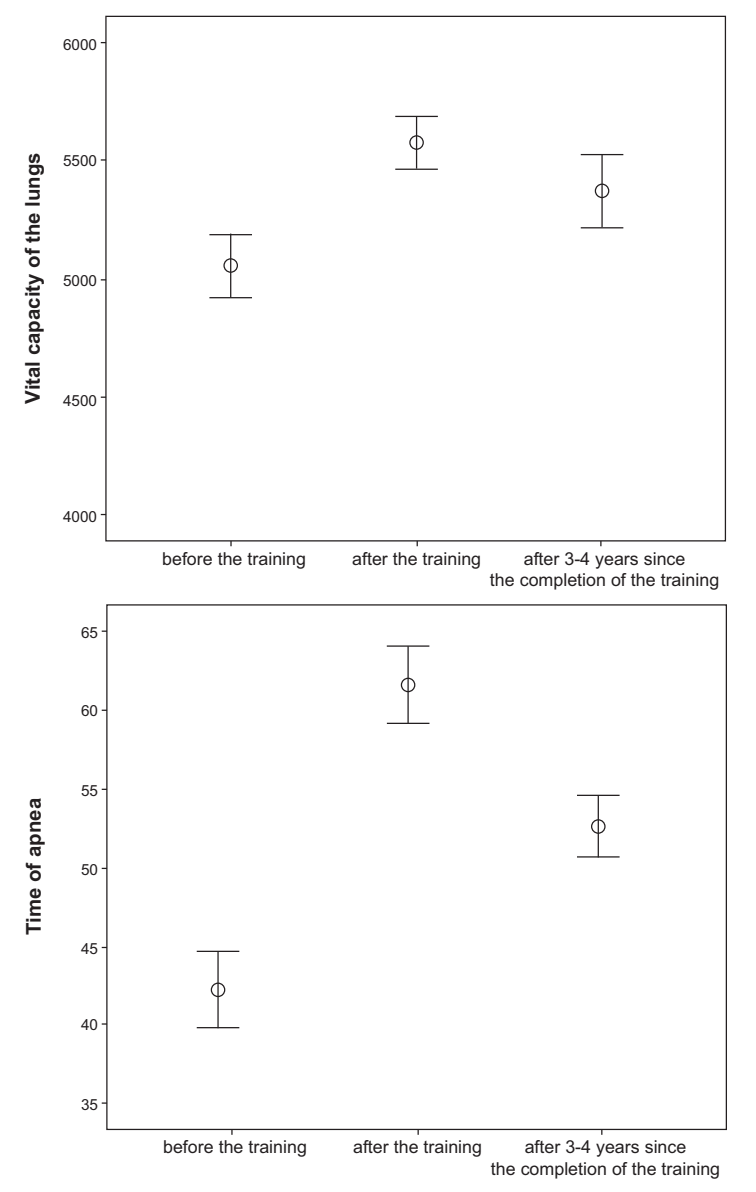

Fig. 2. Difference between before, during and after the training was confirmed in this index amounting to 308.6 $\mathrm{ml}$. This rise was supposed to be associated with a stay in the mountain resort and the performance of intense breathing exercises.

In 1989, Wojtkowiak M. [19] published a set of 10 exercises containing all the elements of physical preparation to effectively perform the L-1 maneuver. Performing these exercises stimulated the functions of the cardiovascular and the respiratory system.

Practicing exercises with elements of apnea caused a high increase in this index by $19.3 \mathrm{~s}$. This result was influenced by the exercises focused on strong pressure of air expiration on the closed glottis. It should be noted that after some years since the training, there occurred a reduction in this index by $-9 \mathrm{~s}$, which could indicate that the pilots performed this exercise rather rarely.

The maximum pressure of air expiration increased after the training by $6.7 \mathrm{mmHg}$. This was mainly due to a combination of isometric muscle tension with a maximum increase in the pressure of air expiration on the closed glottis. This also
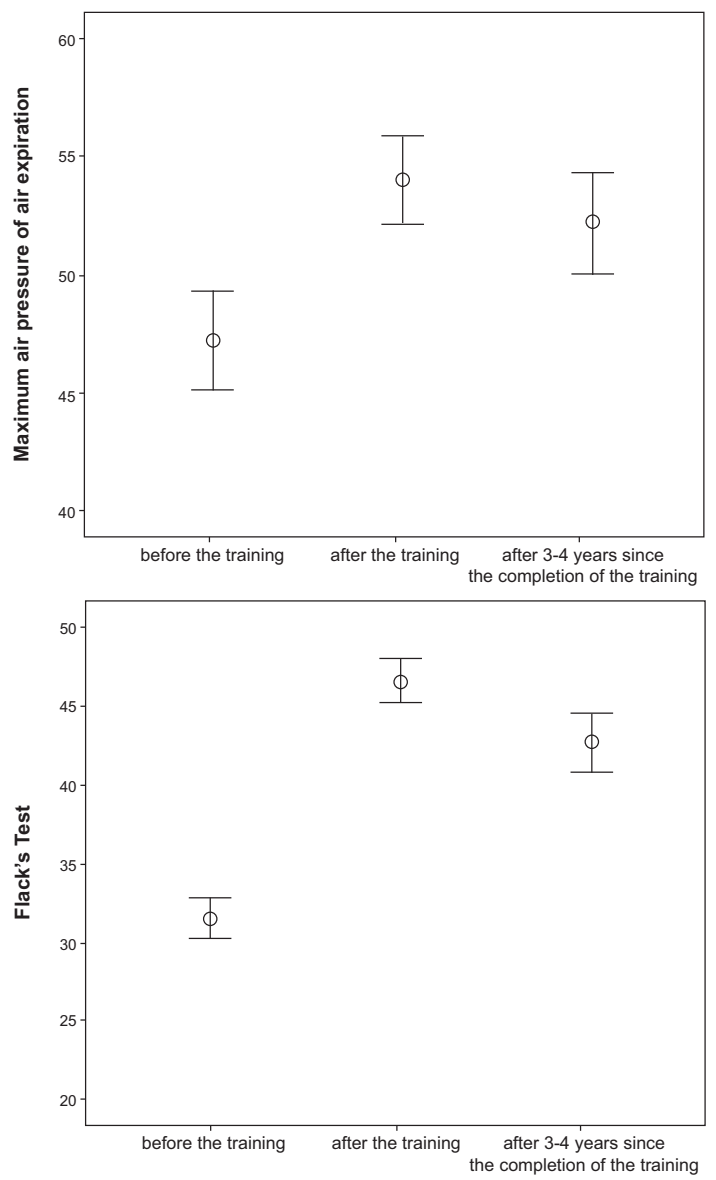
showed the ability to maintain high pressure in the lungs, which resulted in a prolongation of the effectiveness of repeated 3-second cyclic air pressure attempts at the top pressure of air inhalation performed during the L- 1 maneuver. After some years since the training, this index decreased by $1.8 \mathrm{mmHg}$, which could also indicate the lack of practicing this training element.

A substantial increase in the Flack's Test values after the training equaling to $15.1 \mathrm{mmHg}$ was related to the assessment of the skeletal muscles tension together with an increase in the abdominal pressure and with the time of possible sustainance of the determined value of pressure in the lungs during a respiratory arrest. It also allowed for the evaluation of the time of maintaining the effectiveness of the compensatory mechanisms of the circulatory system. After some years since the AGSM training at the training center, this index decreased by $-3.9 \mathrm{mmHg}$.

Summing up the above considerations on the examination of respiratory parameters which were determined 3-4 years since the training, it should be noted that the differences in all these parameters showed a minor decrease, which did not exceed the value of ATL and according to the "Evaluation scale of acceleration tolerance in the linear program" [17] was contained within good limits.

During routine annual tests in the human centrifuge it was possible to notice, in some cases, the differences in the way of breathing in pilots performing L-1 maneuvers. In this study it regarded only three examined pilots. These differences resulted from maneuver adjustments introduced by these pilots that differed from the learned habits acquired during the special training aimed at shaping the AGSM.

The pilots claimed that their conduct is sufficiently effective in the performance of the various maneuvers under the influence of acceleration. No complaints were reported by them concerning increasing fatigue during the flights. It was therefore necessary to check whether the same pilots (from the group of 11 qualified subjects) who practiced L-1 maneuvers at the training center and changed the habits obtained during the training achieved (during the tests in the human centrifuge) equally high ATL results after 3-4 years. The fact that there were no significant differences observed in ATL of these pilots, as compared to the other study subjects, allowed for their inclusion in the group of all examinees during this period.
Errors made or corrections introduced in the L-1 maneuvers by pilots during consecutive maneuvers performed under the influence of acceleration may, over time, lead to earlier fatigue, longer response time, and reducing the effectiveness of the physiological compensation mechanisms of the system and a shift in the ATL threshold.

The slight decrease in ATL after some years since the training was statistically significant, but was contained within the range of values concerning the admission to flying on the level evaluated as a fairly good level [17].

It can therefore be assumed that the results obtained then were associated with less frequent performance of flights under the influence of acceleration and failure to follow the training routine they had acquired while practicing the L-1 maneuvers. It should be noted, however, that even small deviations from the properly executed L-1 maneuvers, relating specifically to maintaining the proper rhythm of the air expiration pressure, may in a few consecutive maneuvers lead to respiratory muscles fatigue and lower ATL.

The problem of muscle fatigue was also stressed by L. Fernandes et al. [10] who studied the activity of various muscle groups, including the intercostal muscles, and by Bain et al. [1] who found that the respiratory muscles become fatigued during AGSM. Buick F. et al. [3] and Eiken et al. [8] dealt with the influence of breathing overpressure under the impact of $+\mathrm{Gz}$ and emphasized the benefits of using compression vests increasing the pressure in the chest. According to these authors, the combined use of AG outfits and L-1 maneuvers allowed to significantly increase ATL and effectively reduce fatigue experienced by pilots. A similar problem was also of interest to other authors $[3,6]$, who emphasized the importance of maintaining for a certain period of time the correct pressure of air expiration on the completely closed glottis.

In the Polish Air Force in order to increase ATL to high $+G z$, major attention was paid to the development of high AGSM efficiency through targeted physical exercises, including the use of compression AG trousers.

This study adopted a similar approach, although it was difficult to accurately determine the correct manner of its implementation by the pilots in aviation units, especially after some years since the basic training. It should be noted that the results could also be affected by various forms of individually performed uncontrolled exercises in aviation units. 


\section{CONCLUSIONS}

1. The exercises introduced in the WOSzK which aimed to increase AGSM influenced significantly the level of ATL and selected respiratory parameters, even after few years.

2. Exercises introduced in WOSzK aiming to increase AGSM significantly affect the level of ATL and selected respiratory parameters
3. The differences in the performance of the L-1 maneuver suggest the need to maintain the continuity of adequate AGSM physical exercises, taking into account the basic elements of the respiratory system efficiency, as part of the annual boot camps.

\section{AUTHORS' DECLARATION:}

Study Design: Mieczysław Wojtkowiak, Marcin Biernacki; Data Collection: Mieczysław Wojtkowiak, Marcin Biernacki; Statistical Analysis: Mieczysław Wojtkowiak, Marcin Biernacki; Manuscript Preparation: Mieczysław Wojtkowiak; Funds Collection: Mieczysław Wojtkowiak, Marcin Biernacki. The Authors declare that there is no conflict of interest.

\section{REFERENCES}

1. Bain, B., Jacobs, l., Buick, F. (1997) Respiratory muscle fatigue during simulated air combat maneuvering (SACM). Aviation Space and Environmental Medicine. 68 (1). 118-125.

2. Baldin, U.I., Myhre, K., Tesch. P.A., Wilphelsen, U., Andersen, H.T. (1985) Isometric abdominal training muscle training and G tolerance. Aviation Space and Environmental Medicine. 56 (2). 120-125.

3. Buick, F., Hartley, J., Pecaris, M. (1992) Maximum intra-thoracic pressure with anti-G straining maneuvers and positive pressure breathing during +Gz. Aviation Space and Environmental Medicine. 63 (8). 670-677.

4. Comens, P., Reed, D., Mette, M. (1987) Physiologic responses of pilots flying high performance aircraft. Aviation Space and Environmental Medicine. 58 (3). 205-210.

5. Convertino, V.A.,et al. (2003) Effects of repeated Valsalva maneuver straining and vasoconstrictive baroreflex responses. Aviation Space and Environmental Medicine. 74 (3). 212-217.

6. Cote, R., Tripp, L., Jennings, T., Karl, A., Goodyear, C., Wiley, R. (1986) Effect of inspiratory volume on intrathoracic pressure generated by L-1 maneuver. Aviation Space and Environmental Medicine. 57 (11). 1035-1038.

7. Dziuk, Z., Sulajnis, H., Wojtkowiak, M. (1969) Współzależność między znoszeniem wyprzyspieszenia +Gz, wynikami prób czynnościowych a rozwojem wybranych cech motorycznych. Postępy Astronautyki. 4. 49-56.

8. Eiken, O., Kolegard, A., Lindborg, B., Mekjavic, J.B., Linder, J. (2003) The effect of straininsg maneuvers on G- protection during assisted pressure breathing. Aviation Space and Environmental Medicine. 74 (8). 822-826.

9. Epperson, W.L., Burton, R.R., Bernauer, E.M. (1982) The influence of differential physical conditioning regimes on simulated aerial combat maneuvering tolerance. Aviation Space and Environmental Medicine. 53 (11). 1091-1097.

10. Fernandes, L., Linder. J., Krock, L.P., Balldin, U.I., Haras-Ringhdahl, K. (2003) Muscle Activity in Pilots With and Without Pressure Breathing During Acceleration. Aviation Space and Environmental Medicine. 74 (6). 626-632.

11. Froom, P., Barzilay, J., Caine, Y. (1986) Low back pain in pilots. Aviation Space and Environmental Medicine. 57 (7). 694695.

12. Sand, D.P., Gigenrath, M., Bock, O. (2003) Production of isometric forces during sustained acceleration. Aviation Space and Environmental Medicine. 74 (6). 633-637.

13. Shubrooks, S.J. \& Leverett, S.D. (1973) Effect of the Valsalva maneuver on tolerance to +Gz acceleration. J. Appl. Physiol.; 34 (4). 460-466.

14. Tesch, A., Hjorst, H., Balldin, U.I. (1983) Effects of strength training on G tolerance. Aviation Space Environmental Medicine 54 (6). 591-595.

15. Truszczyńska, A., Lewkowicz, R., Truszczyński, O., Rąpała, K. (2002) Back pain in Polish military helicopter pilots. International Journal of Occupational Medicine and Environmental Health. 25 (3). 238-264.

16. Więckowski, S., Kowalczuk, K., Wojtkowiak, M. (2009) Badania granicy tolerancji przyspieszeń w wirówce u podchorążych WSOSP w latach 2007, 2008 w porównaniu do lat 1994-2000 Polski Przegląd Medycyny Lotniczej. 15 (4). 387-404. 
17. Wojtkowiak, M. (1976) Assessment of tolerance limits in subjects tested on human centrifuge. Artificial satellites. 11 (1). 29-35.

18. Wojtkowiak, M. (1998) Trening w wirówce przeciążeniowej jako forma przygotowania pilotów do lotów na samolotach wysoko manewrowych. Polski Przegląd Medycyny Lotniczej. 4 (3). 287-301.

19. Wojtkowiak, M. (1989) Wybrane ćwiczenia fizyczne przygotowujące pilotów do wykonywania prób krążeniowo- oddechowych zwiększających tolerancję przyspieszenia. Postępy Astronautyki. 1/2. 83-94.

20. Wojtkowiak, M., Jasiński, T., Domin, A., Kowalczuk, K. (2002) Analiza wyników badań granicy tolerancji przyspieszeń w wirówce przeciążeniowej w latach 1994-2000. Polski Przegląd Medycyny Lotniczej. 8 (3). 255-261.

21. Wojtkowiak, M., Markiewicz, L. (1989) Znaczenie treningu izometrycznego w poprawie tolerancji przyspieszeń w osi +Gz. Medycyna Lotnicza. 102 (1). 30-36.

22. Wojtkowiak, M., Truszczyński, O. Kowalczuk, K. (2006) Set of exercises increasing acceleration tolerance in the high performance aircraft pilots. Physical Activity Sciences. 50. 261-267.

23. Wood, E.H., Lambert, B.H. (1981) Code CF. Involuntary and voluntary mechanisms for preventing cerebral ischaemia due to $+\mathrm{Gz}$ acceleration. The Physiologist. 24. 33-36.

Cite this article as: Wojtkowiak M, Biernacki M: Changes in respiratory parameters some years a training of the L-1 manoeuvere-longitudinal research. Pol J Aviat Med Psychol, 2013; 19(1): 5-12. 